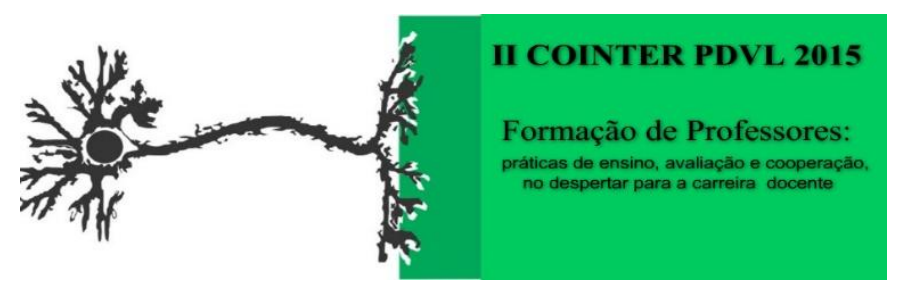

\title{
AVALIAÇÃO NO ENSINO DE QUÍMICA: UM ESTUDO SOBRE AS DISSERTAÇÕES E TESES NO BRASIL
}

\author{
Apresentação: Comunicação Oral
}

SILVA, Natália Maria da ${ }^{1}$; VIEIRA, Welly Evilly da Silva ${ }^{2}$; SILVA, Anelyssa Drielly Josefa da ${ }^{3}$; VIANA, Kilma da Silva Lima ${ }^{4}$.

\section{Resumo}

Este artigo refere-se a um estudo acerca das pesquisas relacionadas à avaliação no ensino de Química, considerando os dados do Banco de Teses da CAPES. Trata-se de uma Pesquisa Bibliográfica que apresenta o objetivo de analisar como está o campo da pesquisa Avaliação em ensino de Química, através as pesquisas existentes no âmbito da Avaliação, Avaliação da Aprendizagem e Avaliação no ensino de Química, tendo, portanto, o intuito de tomar conhecimento sobre como está as discussões nessas áreas. Os resultados encontrados são alarmantes, pois existe uma pequena percentagem de estudo e discussão sobre essas temáticas, especialmente quando se trata da Avaliação relacionada ao ensino de Química. É importante destacar a necessidade de um olhar mais atento para essa disciplina, bem como para as abordagens avaliativas, na perspectiva de reorientar os caminhos que vem trilhando Viana (2014), acredita que é preciso pensar a Avaliação no ensino de química de um modo diferenciado, onde, é necessário que os docentes e discentes dialoguem entre si numa relação de ensino-aprendizagem. Um aspecto a destacar referente a conclusão é o fato de como a abordagem da Avaliação nas pesquisas referentes ao ensino de Química se distância daqueles que deveria predominar na sala de aula, pois nas pesquisas prevalecem aspectos mais históricos, frisando apenas conceitos específicos e memorização, sem se preocupar com a contextualização. É preciso que os pesquisadores da área retratem o verdadeiro sentido de Avaliar, especialmente na área das Ciências Naturais, particularmente em Química.

Palavras chaves: Avaliação, ensino-aprendizagem, Ensino de Química.

\section{Introdução}

Esse trabalho apresenta um estudo acerca das pesquisas na área de avaliação no ensino das Ciências da Natureza no Brasil, especificamente Química, de acordo com dissertações e teses considerando as bases de dados do Banco de Teses da CAPES. Tem-se, portanto a finalidade de analisar como está o campo da pesquisa Avaliação em ensino de Química. Diante disso, iniciamos a

\footnotetext{
${ }^{1}$ Licenciatura em Química, IFPE, campus: Vitória de Santo Antão, nataliasilva119@gmail.com

${ }^{2}$ Licenciatura em Química, IFPE, campus: Vitória de Santo Antão, wellyevilly@hotmail.com

${ }^{3}$ Licenciatura em Química, IFPE, campus: Vitória de Santo Antão, anelyssa_drielly125@hotmail.com

4 Doutora em Avaliação no ensino de Química e Física, IFPE, campus: Vitória de Santo Antão, kilma.viana@vitoria.ifpe.edu.br
} 
pesquisa tendo como palavra-chave "Avaliação", depois "Avaliação da Aprendizagem” e por último a "Avaliação da Aprendizagem no ensino de Química".

Historicamente, essa é uma das disciplinas que mais reprovam no Brasil (LIMA, 2008) e normalmente a vivência avaliativa é típica da Primeira Geração (VIANA, 2014), pois a mesma é centrada naquilo que é mensurável, dando ênfase a medição ou verificação de acertos e erros, não oferecendo maior informação sobre o processo de aprendizagem, preocupando-se apenas em categorizar os objetos da Avaliação (estudantes).

Neste âmbito é importante ressaltar que, devido à abordagem utilizada pelo professor, o ato de ensinar e avaliar no ensino de Ciências influenciam os estudantes em seguir essa área (Rego; Viana, 2014), pois a metodologia na maioria das vezes utilizadas pelos docentes implica na memorização de conceitos e fórmulas, desse modo os estudantes não apresentam bons resultados. $\mathrm{O}$ mapeamento de pesquisas nesta área tem o intuito de tomar conhecimento sobre como está à repercussão e vivência dos objetivos centrais da Avaliação e tornar evidente o quão importante é pesquisas nessa área.

\section{Fundamentação Teórica}

Segundo o minidicionário Aurélio ( $8^{\mathrm{a}}$ edição) avaliar é: “1. Determinar a valia ou valor de. 2. Calcular" , avaliação é : "ato ou efeito de avaliar. 2.valor determinado pelos avaliadores" e avaliador é: “ aquele que avalia ou sabe avaliar”. Desse modo, o avaliador é um indivíduo (nesse caso) que atribui valor a algo ou a alguém, baseando-se em um processo de avaliação que possui parâmetros específicos que objetivam quantificar o objeto avaliado.

O teórico norte-americano Ralph W. Tyler (1978), nomeado como o "Pai da Avaliação Educacional", define a avaliação como um processo de investigação de valores, tendo dessa maneira o pressuposto da eficiência escolar, não se resumindo aos testes escritos, mas aos múltiplos instrumentos avaliativos. Processo esse que buscava avaliar os pontos fortes e fracos em relação aos objetivos pré-estabelecidos. A ênfase estava nos objetivos comportamentais e garantir a qualidade do currículo através da aprendizagem do aluno.

Para Luckesi (2000) os processos avaliativos são meios pedagógicos essenciais à educação, pelos quais docentes e discentes buscariam construir o seu próprio eu, sua vivência e interação social, mas, normalmente a mesma está sendo praticada independente do processo ensinoaprendizagem, tornando-a como um instrumento de ameaça.

Desse modo, torna-se sabido que a avaliação de ensino se diferencia dos exames, já que seus pressupostos partem de aspectos como construtivismo, interação e dinamismo, diferente de exames, 
que estão relacionados à abordagem Tradicional (MIZUKAMI, 1986), que baseiam seus métodos numa aprendizagem excludente e classificatória.

Diante da atual situação que se encontra a avaliação da aprendizagem em escolas brasileiras, Luckesi (2010) afirma que o sistema avaliativo atua meramente na correção de provas e contabilização destes dados, contribuindo para que os estudantes permaneçam na constante mesmice de resolver atividades avaliativas, baseadas simplesmente nos conteúdos estudados para obtenção de nota, na busca da promoção de uma série para outra. Esse comportamento contribui para que a avaliação não seja enxergada como realmente é, uma vez que ela compreende horizontes mais distantes do que simples regras e métodos de contabilização.

Percebe-se então, que a avaliação quando utilizada simplesmente para atribuição de notas, funciona como um processo facilitador de dominação e criador de zonas de conforto entre os integrantes desse ciclo, reforçando uma situação de acomodação que engloba desde alunos até o próprio sistema educacional.

As notas e as provas funcionam como redes de segurança em termos do controle exercido pelos professores sobre seus alunos, das escolas e dos pais sobre os professores, do sistema sobre suas escolas (HOFFMANN, 2001, p.24).

Conforme Hoffman (1993) esse processo torna-se vago, pois compreende apenas a parte objetiva da avaliação, desprezando a parcela subjetiva (que deveria realmente importar) posto que, é ela que defende a interação entre alunos e professores na construção do pensamento crítico e transformador no âmbito escolar no decorrer do processo de ensino-aprendizagem.

Para Viana (2014), a avalição deve ser entendida como parte fundamental no processo de ensino- aprendizagem, pois: é ela que dá informações de como vem sendo desenvolvido tanto o ensino, quanto a aprendizagem. Ela defende que, um dos principais problemas que assolam o ensino, particularmente os das Ciências da Natureza, especialmente Química e Física, é o distanciamento existente entre as teorias da aprendizagem e as teorias de avaliação.

À vista disso, cabe destacar que segundo Viana (2014), apesar de os professores apresentarem metodologias mais participativas e inovadores, diferentes daquelas relacionadas às práticas tradicionais e mais próximas das novas perspectivas de ensino, as suas práticas avaliativas continuam com fortes aspectos excludentes, predominando a ideia de avaliação como instrumento de poder, tendo como objetivo a classificação e comparação entre o rendimento dos estudantes.

Viana (2014) aborda uma perspectiva de avaliação denominada Avaliação da Experiência, onde a mesma coloca em "cheque" as práticas avaliativas que visam medir a aprendizagem do estudante por meio de provas individuais, que propõe a memorização, bem como a matematização no ensino de Química. A mesma respeita a individualidade, apresenta estratégias pedagógicas 
ativas, críticas e reflexiva, além do incentivo ao acolhimento de ideias e o compartilhamento de saberes e responsabilidades.

Vivenciar a Avaliação da Experiência no ambiente escolar é muito difícil? Existe uma grande problemática quando se trata da Avaliação da Experiência, pois apesar da mesma ser uma ferramenta de melhoria de ensino, os professores apresentam metodologia tradicional, visando a educação bancária, e esses fatores impedem que os professores a vivenciem, pois ela requer que os docentes sejam mais dialógicos com os discentes e democráticos. É preciso tornar sabido que a avaliação é um processo contínuo, então os objetivos que a assolam devem ser investidos e incentivamos principalmente pelos docentes, uma vez que, são neles que os estudantes se espelham e principalmente são geradores do conhecimento.

Mencionar as práticas avaliativas utilizadas pelos professores remete em fazer um juízo de valor acerca das Gerações de Avaliação, que segundo Guba e Lincoln (1989), são transformações conceituais pelas quais passou a Avaliação. Percebe-se, entretanto, que apesar das Gerações distinguirem-se umas das outras, cada uma tenta superar os limites das anteriores, preocupando-se apenas em conservar os aspectos positivos das antecedentes.

A Primeira Geração, também conhecida como Pré-histórica da Avaliação (LIMA, 2008), evidencia o julgamento do desempenho dos alunos, nesse âmbito, medida e avaliação eram sinônimos. Segundo Viana (2014), do avaliador se esperava um papel técnico, conhecedor de toda sorte de instrumentos de Avaliação, para todo tipo de variável a ser medida, de tal maneira que, se instrumentos apropriados não existissem, era esperado do avaliador a expertise necessária para criar o instrumento objetivo e apropriado. Essa Primeira Geração caracteriza-se por apresentar avaliação descontextualizada, testes patronizados de caráter quantitativo e individual, a fim de haver comparação e classificação dos objetos da Avaliação (estudantes). Dessa maneira a Educação é descrita através da transmissão de conhecimentos "prontos e acabados".

A Segunda Geração da Avaliação surgiu para tentar superar as deficiências identificadas na primeira, essa geração emerge após a I Guerra Mundial. A mesma pode ser definida como Geração de Descrição (ou Geração da Avaliação por Objetivo), onde não se limitava apenas na medição e sim realizava descrições dos pontos fortes e fracos em relação aos objetivos apontados, buscando descrever o rendimento dos estudantes. Cabe destacar neste âmbito, o "Pai da Avaliação" Ralph Tyler, o qual foi seu principal representante. O papel do professor consistia em planejar estratégias que seriam submetidas aos estudantes, sendo assim, empregava-se Avaliações Somativas, de produto, que visava a descrição dos resultados da aprendizagem dos estudantes relacionados ao alcance de objetivos pré-determinados. 
Nesta fase, medir e avaliar, não eram mais sinônimos mesmo havendo uma preservação de aspectos técnicos da geração antecedente. De acordo com Guba e Lincoln (1989), medir e avaliar são atos distintos, embora a mensuração pudesse ser mais um instrumento a ser usado a serviço da avaliação.

A Terceira Geração, definida por Guba e Lincoln (1989) como a geração de formulação de juízo de valor ou julgamentos, surgiu também a partir das críticas às gerações anteriores, da necessidade de superar os pontos fracos na avaliação das gerações precedentes, a partir do final da década de 50.

No avaliador ainda predomina a característica de descrever e medir o progresso dos estudantes, mas a partir desta fase, o mesmo, começa a determinar o valor e mérito para a tomada de decisão. Essa geração ainda abrangia a quantificação, entretanto com aspectos qualitativos. Cabe ressaltar que o conhecimento não se caracterizava com pronto e acabado, mas se dava através de uma construção, caracterizada por uma relação entre sujeito e mundo, existindo assim, uma preocupação com a construção do conhecimento.

Dessa forma, a Avaliação, relacionava-se, nessa geração, particularmente, com as abordagens cognitivas, onde o professor detinha o papel de conduzir o estudante para uma relação com o mundo, baseando-se em princípios qualitativos. Ela é, antes de tudo, uma avaliação mediadora Hoffman (2001), formativa e reguladora Silva (2004).

Diante das críticas feitas sobre as gerações anteriores, Guba e Lincoln (1989) propõem a Quarta Geração da Avaliação, que, apesar de trazer alguns aspectos das antecedentes, como por exemplo: avaliação mediadora e reguladora, possui como principal objetivo a negociação, juízos, critérios e ações integradas, envolvendo todos os atores do processo avaliativo por meio do diálogo, onde a avaliação passa a ser considerada como processo de aprendizagem permanente.

Segundo Meirelles et al, (2012):

A ideia da avaliação já não somente como modelo, estratégia, ferramenta ou discussão, mas como postura; ou seja, como uma atitude concreta de respeito aos envolvidos no processo avaliativo. Uns e outros se capacitam durante todo o tempo que fazem algo, em um processo contínuo; e desta forma, os avaliadores não são mais que facilitadores, para fazer com que as coisas ocorram.

De um modo geral, nessa geração o professor deixa de ser o único responsável e o estudante passa a ser parte integrante nas ações decisórias, o docente deixa de ser o centro das escolhas e passa a compartilhar as responsabilidades do processo de ensino-aprendizagem, tornando os estudantes protagonistas na construção do conhecimento. 
Comparada às três Gerações anteriores, a Avaliação da Quarta Geração se distingue das outras porque é, antes de tudo, um processo sócio-político, compartilhado e colaborativo, muito associado às abordagens socioculturais do ensino Mizukami, (1986). Cabe destacar que, alguns estudiosos brasileiros da Avaliação apresentam perspectivas que dialogam com a Quarta Geração, como a Avaliação Emancipadora, proposta por Ana Saul (2001) , a Avaliação Formativa Reguladora, proposta por Janssen Silva (2004) e a Avaliação da Experiência, proposta por Viana (2014), por apresentarem perspectivas de uma Avaliação processual, participativa, emancipadora, formativa, contínua, reguladora e negociadora. Como afirmam os autores Guba e Lincoln (1989), apesar das delineadas divisões aqui apresentadas, os critérios utilizados são de natureza didática, pois as diversas abordagens avaliativas coexistem e estão apoiadas em diversos referenciais teóricos e metodológicos.

\section{Metodologia}

Esta pesquisa é de natureza quantitativa, tendo como objetivo investigar e compreender como se configura a Avaliação no ensino de química, pois é importante observar como está a pesquisa nessa área do conhecimento, tomando como base de investigação os dados do Banco de Teses da CAPES, que é um sistema online oficial do governo brasileiro para depósito de teses e dissertações brasileiras, vinculado ao Ministério da Educação (MEC). Os critérios adotados para esse levantamento de dados foram às seguintes:

- Selecionar todos as dissertações e teses que traziam a palavra-chave "Avaliação", verificando o número total de trabalhos que falam sobre avaliação;

- Selecionar todas as dissertações e teses que traziam a palavra-chave "Avaliação da Aprendizagem";

- Dessas dissertações e teses selecionadas, verificar aquelas que tratavam sobre a "Avaliação no ensino de Química”.

- Leitura dos resumos e conclusões desses trabalhos;

- Leitura completa das teses e dissertações que indicassem, após a seleção, discussão sobre Avaliação no ensino de química.

\section{Resultados e Discussão}

Verificamos, após as analises, que trabalhos de teses e dissertações na área de "Avaliação", especificamenteno ensino das ciências naturais ainda é pouco discutido, especialmente no ensino de Física e Química. E quando buscamos pesquisa em “Avaliação da Aprendizagem” esses dados se 
afunilam ainda mais. E com relação às pesquisas em “Avaliação no ensino de Química” existe uma pequena porcentagem em pesquisas e discussões dessa temática.Comparando esses dados, observe a Tabela abaixo:

Tabela 1: CAPES X Avaliação. Fonte: Própria

\begin{tabular}{lc}
\multicolumn{1}{c}{ Artigos } & Numero de Publicações \\
\hline Avaliação & 23092 \\
Avaliação da aprendizagem & 1345 \\
Avaliação no ensino de Química & 87
\end{tabular}

Através, dessa tabela é possível observar claramente o quanto pesquisa em Avaliação em si é pouco discutida e pesquisada, em especial quando se trata de Avaliação no ensino de química, observamos os seguintes dados:

- Um total de 23092 trabalhos encontrados na plataforma CAPES, fazem referência em Avaliação;

- Apenas 1345 fazem referencia á Avaliação da Aprendizagem e apresentam discussões significativas no corpo do texto.

- Dentre os 87 que discutem Avaliação no ensino de Química, é notório que a ênfase maior está nos conceitos químicos e não na prática avaliativa ou nos métodos avaliativos.

Ao analisamos esses dados percebemos que dentre as Dissertações e Teses encontradas correspondentes aos 87 que discutem Avaliação no ensino de química, poucas de fato apresentam discussões aprofundadas na área especifica de avaliação no ensino aprendizagem dos estudantes.

Apesar de a Avaliação ser citada no título do trabalho, na maioria das vezes, são as questões específicas que estão em xeque, relacionadas aos conceitos, conteúdos propriamente ditos e não mencionam como deveria avaliar, ou melhor, qual seria a verdadeira essência da Avaliação no ensino de Química.

\section{Conclusões}

Diante dessas análises, é perceptível que há uma pequena percentagem de produção e discussão em relação à área de Avaliação, especialmente no ensino de Química.

Normalmente quando se produz no campo da Avaliação relacionando com ensino de Química, a preocupação maior está em destacar a importância nos conceitos ou conteúdos, deixando a desejar o processo de ensino-aprendizagem-avaliação. A fundamentação teórica dessas teses e dissertações encontradas na plataforma do Banco Teses da CAPES, é bastante alarmante, 
pois eles (autores) quase não referenciam os teóricos que discutem Avaliação. Por conseguinte, as análises dos dados dão ênfase aos aspectos quantitativos, não tendo um embasamento teórico mais aprofundando.

Segundo (REGO; VIANA, 2014) é a pesquisa e discussão em eventos, periódicos que estimulam a mudança da realidade principalmente nas salas de aulas, uma vez que, estamos tratando de discussões sobre a relação existente entre Avaliação e aprendizagem, e, consequentemente, aflora o interesse por essa área do conhecimento.

\section{Referências}

GUBA, E. G.; LINCOLN, Y. S. Fourth generation evaluation. Newbury Park, London, New Delhi: Sage, 1989.

HOFFMAN, J. Avaliação mediadora: uma prática em construção da pré-escola à universidade. Porto Alegre: Mediação, 2001.

LIMA, K. S. Compreendendo as concepções de avaliação de professores de física através da teoria dos construtos pessoais. Recife, 2008. 163 p. Dissertação (Ensino das Ciências). Departamento de Educação, UFRPE, 2008.

LUCKESI, C. C. Avaliação da aprendizagem escolar: estudos e preposições- 21 ed. - São Paulo: Cortez, 2010.

MEIRELLES, M. C. P. et al. Avaliação de quarta geração: reciclagem de dados. Rio Grande do Sul, 2012. P63-74.

MINI AURÉLIO. O dicionário da Língua Portuguesa. $8^{\circ}$ edição, Fevereiro de 2012.

MIZUKAMI, M. G. N. Ensino: as abordagens do processo. São Paulo: EPU, 1986.

TYLER, R. W. Basic Principles of Curriculum and Instruction. Chicago, University of Chicago Press, 1978.

REGO, A. M. C; ARAÚJO, R. M. ; VIANA, K.S.L. As Gerações da Avaliação e suas relações com o ensino de Química. Anais do I Simposio Latinoamericano de Intercambio sobre Ensiñanza de la Química, La Plata - Argentina, 2014.

SAUL, A. M. A. S. A Avaliação Educacional. São Paulo, 2001.

SILVA, J. F. Avaliação na perspectiva Formativa-Reguladora: Pressupostos Teóricos e Práticos. Porto Alegre: Mediação, 2004.

VIANA, K. S. L. Avaliação da Experiência: uma perspectiva de Avaliação para o ensino das Ciências da Natureza. 2014. 202f. Tese (Ensino de Ciências - Física e Química) - Universidade 
Federal Rural de Pernambuco - UFRPE, Recife, 2014. 